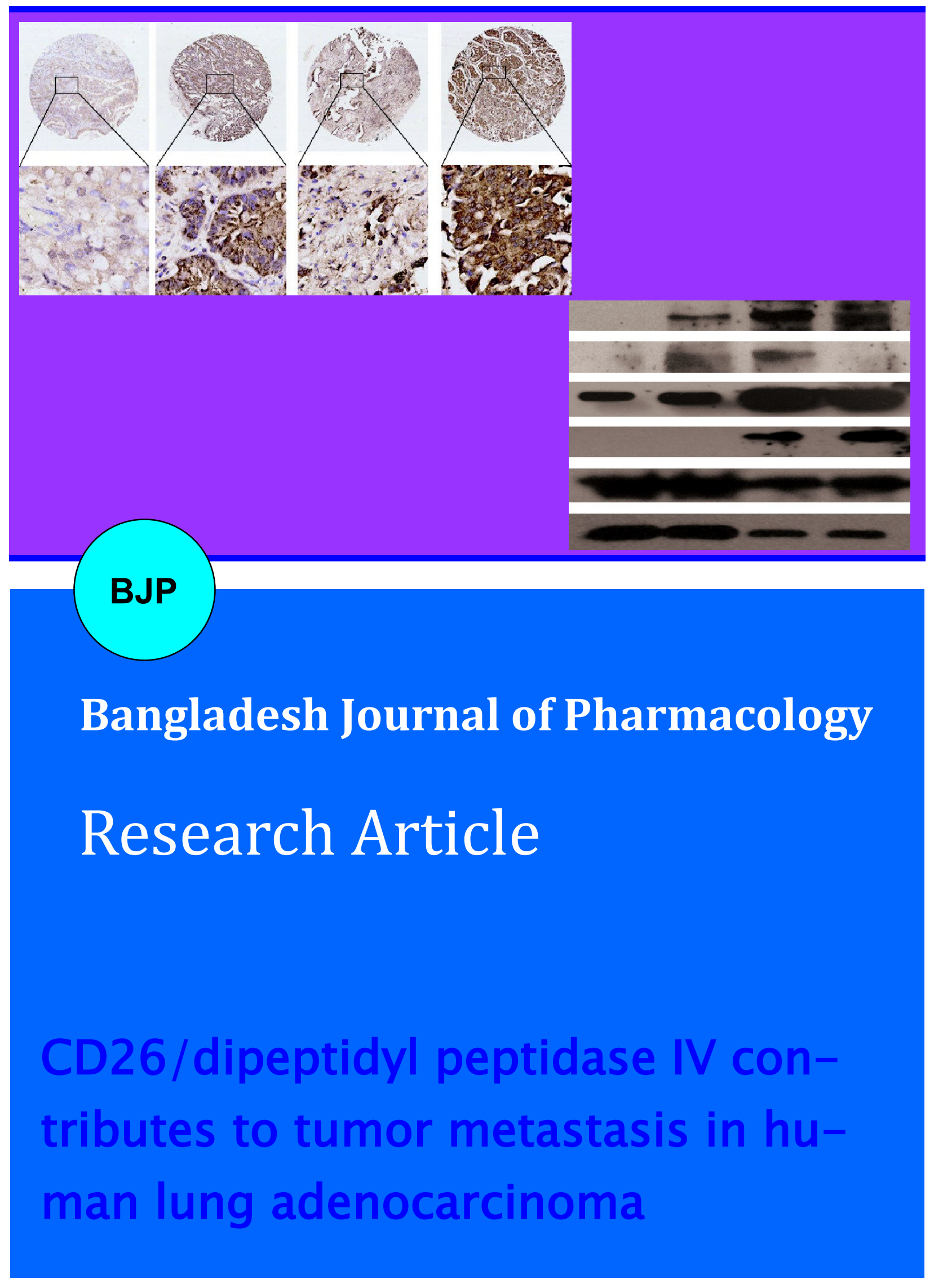


Abstracted/indexed in Academic Search Complete, Agroforestry Abstracts, Asia Journals Online, Bangladesh Journals Online, Biological Abstracts, BIOSIS Previews, CAB Abstracts, Current Abstracts, Directory of Open Access Journals, EMBASE/Excerpta Medica, Google Scholar, HINARI (WHO), International Pharmaceutical Abstracts, Open J-gate, Science Citation Index Expanded, SCOPUS and Social Sciences Citation Index

ISSN: $1991-0088$

\title{
CD26/dipeptidyl peptidase IV contributes to tumor metastasis in human lung adenocarcinoma
}

\author{
Lei Liu, Mingxia Yan, Fangyu Zhao, Jing Li, Chao Ge, Qin Geng, Miaoxin Zhu, Lei Sun, \\ Xianghuo He, Jinjun Li and Ming Yao
}

State Key Laboratory of Oncogenes and Related Genes, Shanghai Cancer Institute, Renji Hospital, Jiao Tong University School of Medicine, Shanghai, P.R. China.

\begin{tabular}{|c|c|}
\hline \multicolumn{2}{|l|}{ Article Info } \\
\hline Received: & 6 April 2013 \\
\hline Accepted: & 13 April 2013 \\
\hline Available Online: & 3 May 2013 \\
\hline \multicolumn{2}{|c|}{ DOI: 10.3329/bjp.v8i2.14404 } \\
\hline \multicolumn{2}{|c|}{$\begin{array}{l}\text { Cite this article: } \\
\text { Liu L, Yan M, Zhao F, Li J, Ge C, } \\
\text { Geng Q, Zhu M, Sun L, He X, Li J, } \\
\text { Yao M. CD26/dipeptidyl peptidase } \\
\text { IV contributes to tumor metastasis in } \\
\text { human lung adenocarcinoma. Bangla- } \\
\text { desh J Pharmacol. 2013; 8: 198-206. }\end{array}$} \\
\hline
\end{tabular}

Abstract
CD26/dipeptidyl peptidase IV (DPPIV) is a 110-kDa trans-membrane ecto-
enzyme that has multiple functions in humans. Previously, we established a
highly metastatic human lung adenocarcinoma cell line exhibiting epithelial-
mesenchymal transition (EMT) by in vivo selection in NOD/SCID mice and
performed microarray analysis; we showed that CD26 expression was higher
in SPC-A-1sci cells compared to SPC-A-1 parent cells. The effect of CD26 over
-expression in lung adenocarcinoma is unclear. In the current study, through
Matrigel invasion and metastasis assays and Western blotting assay, we
found that CD26 regulated the invasion and metastasis of lung
adenocarcinoma cells and that the expression of CD26 correlated with the
expression of proteins involved in EMT. The results from human lung
adenocarcinoma tissue microarrays showed that CD26 was highly expressed
in poorly differentiated lung adenocarcinomas compared to highly
differentiated cancers. These results suggest that CD26 has a tumor-
promoting function and is a putative prognostic marker for lung
adenocarcinoma in patients.

\section{Abstract} enzyme that has multiple functions in humans. Previously, we established a highly metastatic human lung adenocarcinoma cell line exhibiting epithelialmesenchymal transition (EMT) by in vivo selection in NOD/SCID mice and performed microarray analysis; we showed that CD26 expression was higher in SPC-A-1sci cells compared to SPC-A-1 parent cells. The effect of CD26 over Matrigel invasion and metastasis assays and Western blotting assay, we found that CD26 regulated the invasion and metastasis of lung adenocarcinoma cells and that the expression of CD26 correlated with the expression of proteins involved in EMT. The results from human lung adenocarcinoma tissue microarrays showed that CD26 was highly expressed in poorly differentiated lung adenocarcinomas compared to highly differentiated cancers. These results suggest that CD26 has a tumoradenocarcinoma in patients.

\section{Introduction}

Lung cancer is the leading cause of cancer deaths and the 5-year survival rate is less than 14\% (Lee et al., 2012). Metastasis of tumor cells to distant organs is the primary cause of lung cancer fatalities. Understanding the biological mechanism of metastasis is important for the development of new treatment strategies and for the identification of predictive metastatic markers. Growing evidence has identified CD26/ dipeptidyl peptidase IV (DPPIV) as a gene that affects the invasiveness of many tumor cells (Pang et al., 2010; Sun et al., 2008; Dourada et al., 2007; Wesley et al., 2005; Pro and Dang, 2004; Lefort and Blay, 2011), but little is known about the role of CD26 during metastasis and invasion of human lung cancer.
D26 has multiple biological functions and is expressed on a variety of cell types, including $\mathrm{T}$ lymphocytes, endothelial cells, and epithelial cells (Pro and Dang, 2004; Thompson et al., 2007; Hiramatsu et al., 2003). Recently, CD26 was shown to promote human colorectal cancer metastasis as cancer stem cells (Dourada et al., 2007).

Epithelial-mesenchymal transition (EMT) plays an important role during tumor metastasis (Guarino et al., 2007). Previously, the EMT program was shown to exist in lung cancer and was predictive of poor prognosis in lung cancer patients (Prudkin et al., 2009; Chou et al., 2009). The precise role of CD26 during EMT remains unclear despite evidence suggesting a link between CD26 and the EMT program (Pang et al., 2010). 
Previously, we established a highly metastatic human lung adenocarcinoma cell line, SPC-A-1sci, that exhibits high CD26 expression and the EMT phenomenon (Jia et al., 2010). In the present study, we transfected the lung adenocarcinoma cell lines SPC-A-1 and SPC-A-1sci with CD26 cDNA and shRNA to overexpress and inhibit CD26 expression, respectively. By using in vitro Matrigel invasion and metastasis assays, we found that CD26 inhibition significantly decreased the invasive and migratory capacity of transfected cells. In contrast, CD26 overexpression increased the invasive and migratory capacity of cells. Western blotting analysis revealed that CD26 overexpression lead to an increase in $\mathrm{N}$-cadherin and vimentin, and the results were reversible. There was no visible change in the expression of $\beta$ -catenin and fibronectin in infected cells. A human lung adenocarcinoma tissue chip revealed a positive correlation between CD26 expression and degree of lung adenocarcinoma differentiation. Overall, we identified a positive effect of CD26 on metastasis and invasion in lung adenocarcinoma, and the human lung adenocarcinoma tissue chip indicated that CD26 might be associated with the differentiation of lung adenocarcinoma.

\section{Materials and Methods \\ Cell lines and cell culture}

Human lung adenocarcinoma SPC-A-1 cells were obtained from the Cellular Institute of Chinese Academy of Science (Shanghai, China). SPC-A-1sci cells were established in our lab by in vivo selection in NOD/ SCID mice (Jia et al., 2010). The 293T cell line was purchased from the ATCC (American Type Culture Collection). Cells were cultured in Dulbecco's modified Eagle's medium (DMEM) supplemented with 10\%fetal bovine serum (FBS, Biowest), $100 \mathrm{U} / \mathrm{mL}$ penicillin, and $100 \mu \mathrm{g} / \mathrm{mL}$ streptomycin at $37^{\circ} \mathrm{C}$ in a $\mathrm{CO}_{2}$ humidified chamber.

\section{Lentivirus packaging and cell infection}

$293 \mathrm{~T}$ cells were maintained in DMEM supplemented with $10 \%$ FBS. The day before transfection, the cells were seeded in a $10 \mathrm{~mm}$ dish. The pLV-ORF-CD26 or pLV vector and pPACK Packaging Plasmid Mix (GeneCopoeia ${ }^{\mathrm{TM}}$ ) were co-transfected according to the manufacturer's instructions. The supernatant was harvested 48 hours after transfection, cleared by centrifugation at 3,000 rpm at room temperature for $10 \mathrm{~min}$, and passed through a $0.45 \mathrm{~m}$ syringe filter. The viral titer was measured according to the expression level of GFP following the manufacturer's instructions. The packaged lentivirus was named LV-CD26+ and LV-NC.

The LV-shRNA-CD26 and LV-shRNA-NC were purchased from Shanghai GenePharma.

SPC-A-1 cells were infected with LV-CD26+ or LV-NC;
SPC-A-1sci cells were infected with LV-shRNA-CD26 and LV-shRNA-NC. The infection efficiency was assessed by visualizing GFP under a fluorescent microscope.

\section{Real-time quantitative PCR}

The following procedures were conducted as previously described (Jia et al., 2010). Briefly, Trizol reagent (Invitrogen, US) was used to extract total RNA from cultured cells according to the manufacturer's instructtions. cDNA was reverse transcribed using the manufacturer's protocol, enzymes, and reagents (Takara, Japan). Real-time PCR was performed using 7300 RealTime PCR system with SDS RQ Study software (Applied Biosystems, US). cDNA was amplified in a SYBR Green premix with Rox (Takara, Japan). The primers used for the quantitative PCR were as follows:

CD26 forward: 5'-CATACAAATCACTGCTCCTG-3';

CD26 reverse: 5'-GCCTAAATCTTCCAACCC-3';

$\beta$-actin forward: 5'-AGTGTGACGTGGACATCCGCAAAG-3';

$\beta$-actin reverse: 5'-ATCCACATCTGCTGGAAGGTGGAC-3'.

Gene expression was normalized to $\beta$-actin. All reactions were run in triplicate.

\section{Western blotting}

All cells were washed 3 times with PBS, lysed in cell lysis buffer $(20 \mathrm{~mL}$ of $5 \times$ loading buffer, $4 \mathrm{~mL}$ of $20 \times$ DTT, diluted in deionized water to $1 \times$ ), and heated at $100^{\circ} \mathrm{C}$ for $10 \mathrm{~min}$. The samples were resolved on an $8 \%$ SDS-PAGE gel and transferred onto a nitrocellulose membrane. The primary antibodies used for immunoblotting were as follows: Anti-CD26 (BD, US), anti-Ecadherin (Santa Cruz, US), anti-N-cadherin (Santa Cruz, US), anti-fibronectin (Abcam, US), anti- $\beta$-catenin (Abcam, US) and anti-vimentin (DAKO, Denmark). Anti-mouse HRP and anti-rabbit HRP (Sigma-Aldrich, US) were used as secondary antibodies. All protein samples were normalized to the endogenous protein, $\beta$ actin (Abcam, US).

\section{In vitro proliferation assay}

In all, $200 \mu \mathrm{L}$ of SPC-A-1-CD26+, SPC-A-1-NC (control), SPC-A-1sci-CD26-, or SPC-A-1sci-NC (control) cells were seeded in a 96-well microtiter plate at $1 \times 10^{4}$ cells $/ \mathrm{mL}$. The cells were incubated for 1 to 7 days. Two hours prior to the end of incubation, $10 \mu \mathrm{L}$ of CCK8 (Dojindo Corp, Shanghai, China) was added to each well. After the incubation, the optical density (OD) of each sample was measured at a wavelength of $450 \mathrm{~nm}$ and compared to the reference wavelength at $600 \mathrm{~nm}$. All experiments were performed three times, and the average of the results was calculated.

\section{In vitro colon formation assay}


In all, $10 \mu \mathrm{L}$ of SPC-A-1-CD26+, SPC-A-1-NC, SPC-A1sci-CD26-, or SPC-A-1sci-NC cells were seeded in a 24well microtiter plate at a concentration of $1 \times 10^{4}$ cells / $\mathrm{mL}$ and cultured at $37^{\circ} \mathrm{C}$ under $5 \% \mathrm{CO}_{2}$ for two weeks. The wells were washed with PBS and stained with crystal violet. The resulting colonies were photographed from three random fields per well; images were obtained from three experimental replicates, and the number of colonies was counted.

\section{In vitro migration and invasion assay}

Assays were per-formed using $8 \mu \mathrm{m}$ pore Transwell chambers (Corning) as described previously with slight modifications (Baumann et al., 2005). Briefly, cells were seeded at 25,000 cells per well into Transwell chambers for migration assays or at 50,000 cells per well into matrigel-coated Transwell chambers for invasion assays. The wells were washed with PBS after 16 hours for migration assays or after 24 hours for invasion assays. Cells that remained in the upper chamber were removed with a cotton swab, and the entire chamber was fixed and stained with crystal violet. Migrated cells were counted using a CKX41 microscope (Olympus, Japan). Images from three random fields from three replicate wells were obtained.

\section{Immunohistochemistry}

Human lung adenocarcinoma tissue samples were obtained from patients following informed consent according to a protocol approved by the Ethics Committee of Shanghai Jiao-Tong University School. Matched pairs of lung adenocarcinoma tissues and matched adjacent noncancerous tissues were used to generate the tissue microarray (Shanghai Biochip Co., Ltd. China), as previously described (Kononen et al., 1998). There were 204 lung adenocarcinoma tissues and matched adjacent noncancerous tissues in the tissue microarray. The 102 lung adenocarcinoma tissues were classified as follows: highly differentiated tissue $(n=11)$, mid-range differentiated tissue $(n=47)$, poorly differentiated tissue $(\mathrm{n}=44)$. Immunohistochemical staining was performed to detect CD26 expression in lung adenocarcinoma tissues and the matched non-cancerous tissues. The primary antibody against CD26 was obtained from Abcam (1:200). The percentage of positive cells that were stained was scored as follows: less than $5 \%$ was given a score of $0,5-24 \%$ was given a score of 1,25 $-49 \%$ was given a score of $2,50-74 \%$ was given a score of 3 , and more than $74 \%$ was given a score of 4 .

\section{Statistical analysis}

The results are presented as the mean \pm SD. Comparisons of quantitative data between two groups were analyzed by Student's t-test (two-tailed; $p<0.05$ was considered significant). A $\chi^{2}$ test was used for categorical data when appropriate. Analysis was performed with SPSS 15.0 for Windows.

\section{Results}

\section{Expression of CD26 in transfected lung cancer cells}

Real-time PCR and Western blotting were conducted to determine CD26 expression levels in transfected lung cancer cells. The results showed that CD26 was expressed in SPC-A-1sci-NC and SPC-A-1-CD26+ cell lines (Figure 1).

\section{CD26 inhibited cellular proliferation potential}

Cell proliferation and colonization are prerequisites for tumor metastatic progression. Compared to the control population, the proliferative capacity of CD26- cells was more aggressive, and CD26 ${ }^{+}$cells were less aggressive (Figure 2A, B). Thus, the increased metastatic activity of

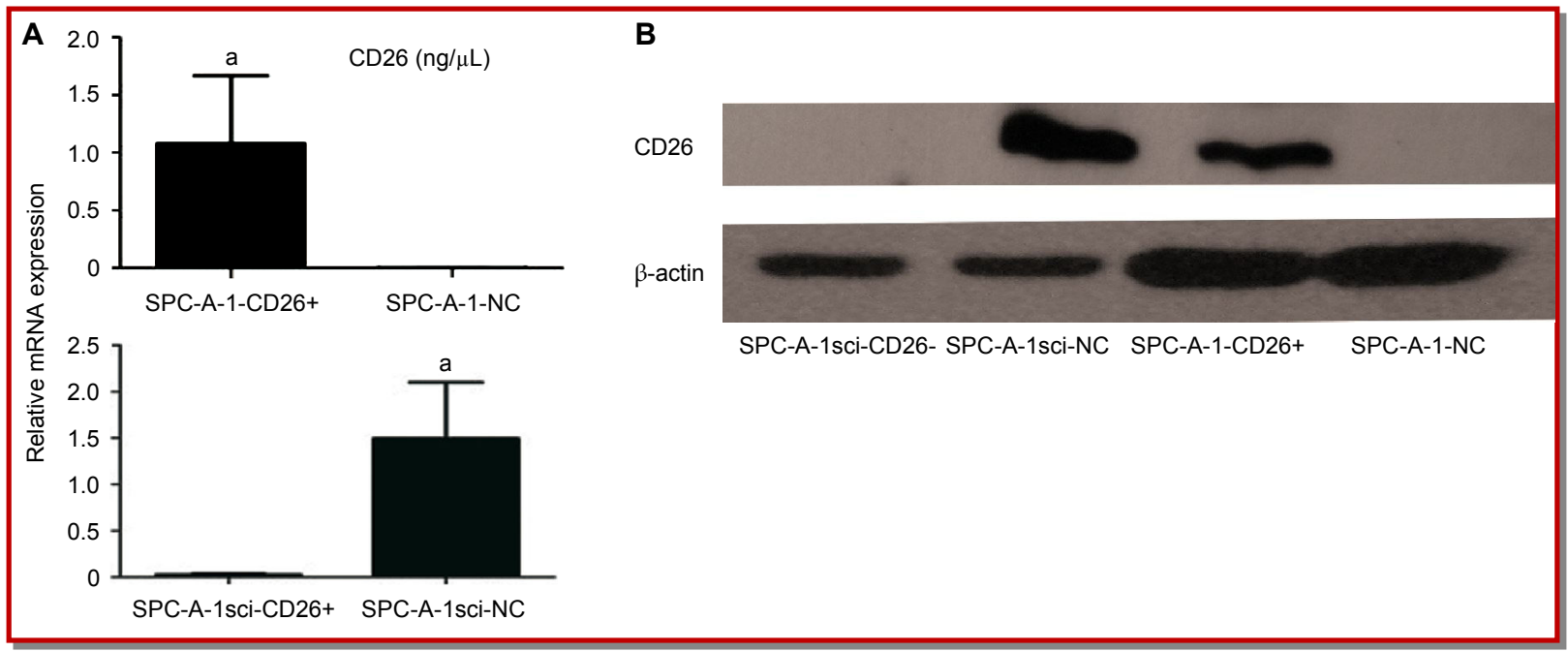

Figure 1: Expression of CD26 in transfected lung cancer cells. (A) Quantitative-PCR analysis of the CD26 mRNA levels in transfected cells. The results are expressed as the mean \pm SD; a $<0.01$. (B) Detection of CD26 in transfected cells by immunoblotting. $\beta$-actin was used as a loading control 


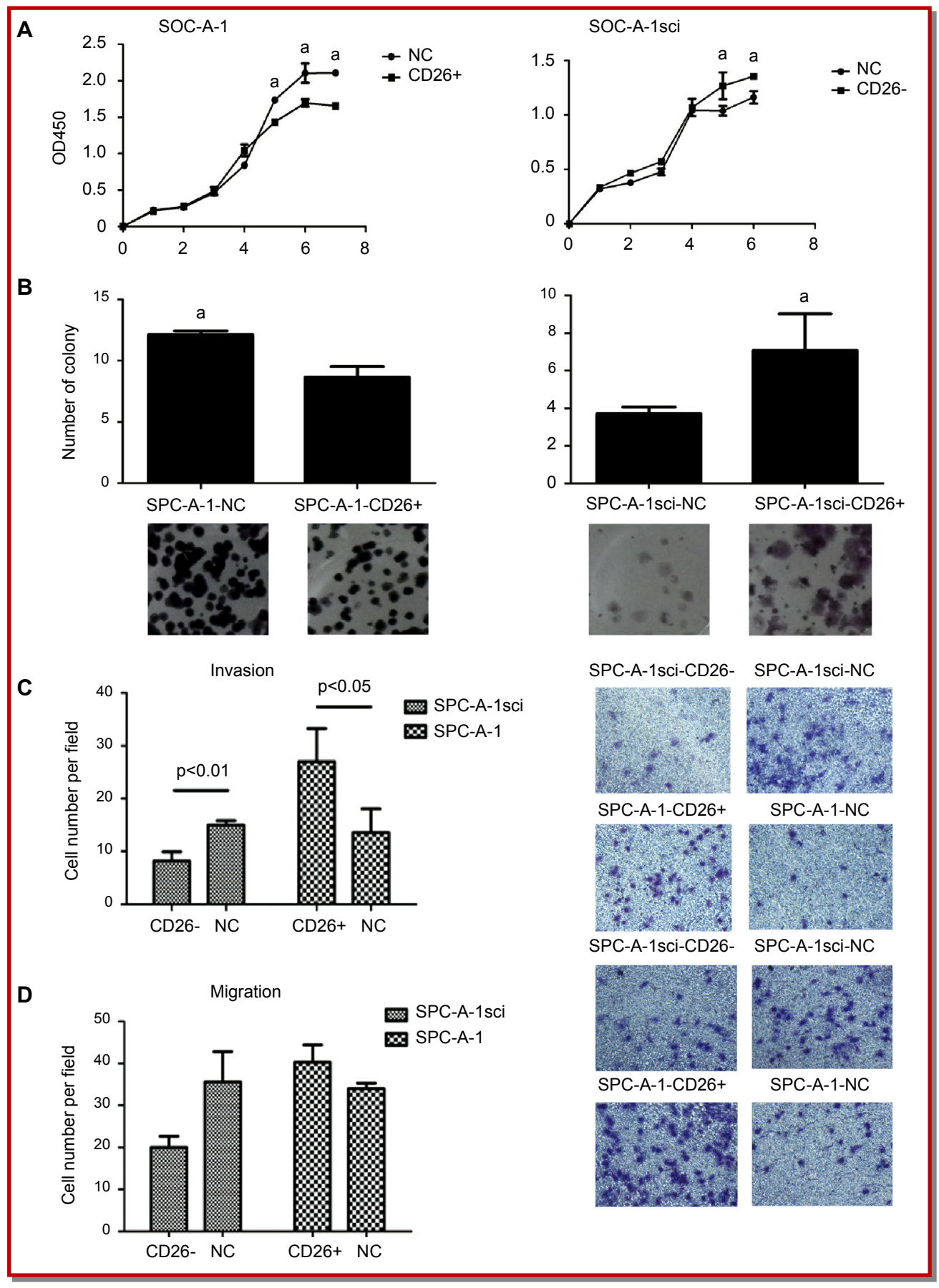

Figure 2: Effects of CD26 expression on cell migration and invasion. (A) In vitro growth curves for infected cells. Cells $(2 \times 104 /$ well) were seeded in 96-well plates, and cell proliferation was measured by a CCK8 assay. The results are expressed as the mean \pm SD; ap<0.05. (B) Cell colony formation of infected cells. Cells $\left(1 \times 10^{4} /\right.$ well $)$ were cultured in 24 -well plates. Colonies were photographed and counted after two weeks. The results are expressed as the mean $\pm \mathrm{SD}$; ${ }^{\mathrm{p}}<0.05$. (C and $\left.\mathrm{D}\right)$. Transwell invasion and migration assays with infected cells. For invasion assays (C), cells $\left(1 \times 10^{5} /\right.$ well $)$ were seeded into Matrigel-coated Transwell plates and cultured for 24 hours at $37^{\circ} \mathrm{C}$. For migration assays (D), cells $\left(2.5 \times 10^{4} /\right.$ well) were seeded into non-coated Transwell plates and cultured for 16 hours at $37^{\circ} \mathrm{C}$. The cells that had invaded or migrated to the underside of the inserts were then stained with $\mathrm{H}$ and $\mathrm{E}$, photographed (lower) and quantified (upper) at 400× magnification. All experiments were repeated three times. The results are expressed as the mean $\pm \mathrm{SD}$

SPC-A-1sci cells is due to the acquisition of other metastasis-promoting properties, and not due to a faster growth rate.

\section{CD26 expression increased the cellular potential for migration and invasion}

We next characterized other cellular properties that 


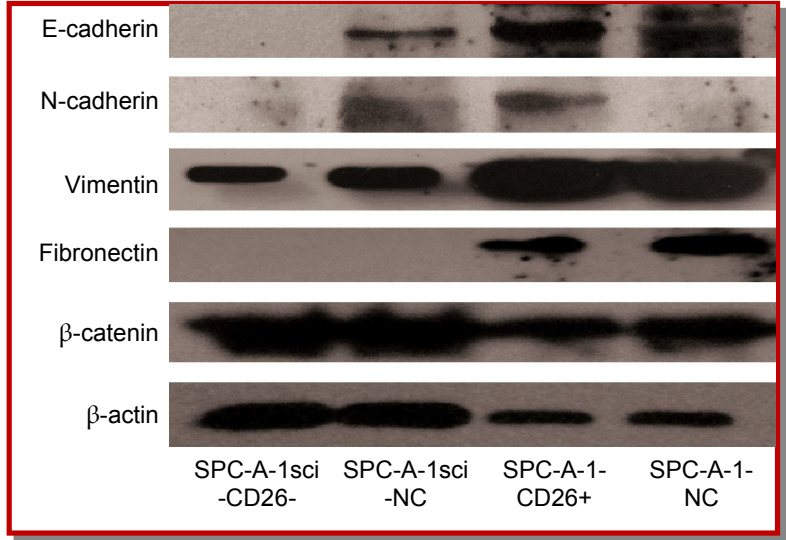

Figure 3: Effects of CD26 expression on EMT-associated molecules. visible upregulation of E-cadherin and $\mathrm{N}$-cadherin was observed after CD26 was overexpressed. Expression of vimentin was higher in SPC-A-1-CD26+ and SPC-A-1sci-NC cells compared to other cells. The expression of fibronectin and $\beta$-catenin was unchanged in infected cells

might be relevant to metastasis. Using a Transwell migration assay, we found that $\mathrm{CD} 26^{+}$cells were more mobile than CD26- cells (Figure 2D). We also determined the invasive abilities of $\mathrm{CD}^{2} 6^{+}$and CD26- cells using Transwell invasion assays, and significantly more $\mathrm{CD} 26^{+}$cells were found to invade the basal side of the membrane compared to CD26- cells (Figure 2C). Therefore, CD26+ cells acquire an enhanced ability to migrate and invade, and these features may account for their highly metastatic behavior in vivo.

\section{Association of CD26 expression with EMT}

Loss of cell-cell interactions and the acquisition of migratory properties are characteristics often associated with epithelial-mesenchymal transition (EMT) of cells and tumor invasion (Yang and Weinberg, 2008). Loss of E-cadherin-mediated cell-cell interaction is essential for EMT Peinado et al., 2004). N-cadherin, a crucial mediator of homotypic and heterotypic cell-cell interactions, may play a central role in metastasis (Lammens et al., 2012). Long been regarded as an oncogene, $\beta$-catenin is critical for regulating cellular processes, including motility and invasion (Webb et al., 2012; Shen et al., 2011). We therefore evaluated the expression of Ecadherin, $\mathrm{N}$-cadherin, $\beta$-catenin, and the E-cadherin repressors, fibronectin and vimentin, in $\mathrm{CD} 26^{+}$versus CD26- cells using Western blotting (Figure 3). Vimentin expression was upregulated in lysates of $\mathrm{CD}^{2} 6^{+}$cells compared to NC cells. A concomitant upregulation of E -cadherin and N-cadherin was observed in CD26+ cells. The expression of $\beta$-catenin and fibronectin was unchanged in infected cells. These results suggest that the EMT-like attributes contribute to the invasive phenotype and metastatic capacity of the CD26 cell lines.

\section{Correlations between CD26 and clinicopathologic features}

As shown in Table I, we detected and compared tissue

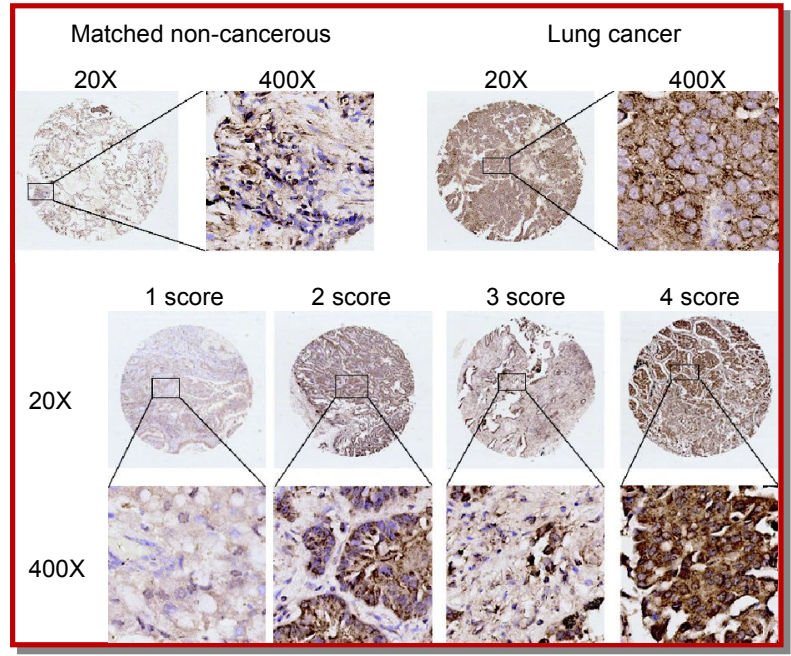

Figure 4: CD26 expression in lung cancer was associated with histological grade. Immunohistochemical staining of CD26 in lung cancer tissues and paired adjacent noncancerous tissues. The staining was scored. Scoring was measured by the percentage of positive cells with the following staining intensities: less than 5\% scored " 0 "; 5-24\% scored " 1 "; $25-49 \%$ scored "2"; $50-74 \%$ scored " 3 "; and more than $74 \%$ scored " 4 "

CD26 protein levels from 102 patients with lung adenocarcinoma. Tissue CD26 levels were significantly higher in primary adenocarcinoma tissues compared to normal adjacent tissues $(\mathrm{p}<0.0001$; Figure 4$)$. Further analysis showed that CD26 levels were higher in patients who were 60 years of age and younger than in patients who were older than $60(\mathrm{p}<0.05)$. In addition, CD26 levels were higher in poorly differentiated lung adenocarcinoma tissues compared to highly differentiated samples $(\mathrm{p}<0.05)$. There was a trend indicating that the presence of distant metastasis correlated with the expression of CD26 (data not shown). With respect to clinicopathologic features, we found that high levels of CD26 correlated with age and histological grade in lung adenocarcinoma patients, indicating that CD26 plays an important role in lung adenocarcinoma.

\section{Discussion}

CD26/DPPIV is a serine-type exopeptidase that has several physiological functions in human cells. Previous studies on CD26 have yielded various results in different cancers. Preclinical studies have shown that increased CD26 expression inhibits metastasis in ovarian cancer (Kajiyama et al., 2010) and that the suppession of CD26 promotes metastasis in prostate cancer (Sun et al., 2008). In contrast, the inhibition of CD26 in renal cell carcinoma decreases tumor growth and reduces the binding of cancer cells to fibronectin and collagen (Inamoto et al., 2006). Clinical studies in thyroid cancer and gastrointestinal stromal tumors have suggested that CD26 expression is associated with distant metastasis or recurrence after resection (Yamaguchi et al., 2008). The pleiotropic effects of CD26 may 
Table I

\begin{tabular}{|c|c|c|c|c|c|}
\hline Correlation & en CD26 exp & $\begin{array}{r}\text { on in lung ade } \\
\text { characte }\end{array}$ & $\begin{array}{l}\text { carcinoma patie } \\
\text { tics }\end{array}$ & $s$ and their clini & hologic \\
\hline \multirow[t]{2}{*}{ Clinical pathology } & \multicolumn{4}{|c|}{$\mathrm{LC}, \mathrm{n}=102$} & \multirow[t]{2}{*}{$\mathrm{p}$ value } \\
\hline & $\mathrm{CD} 26(1+) \mathrm{n}=8$ & $\mathrm{CD} 26(2+) n=24$ & CD26(3+) n $=38$ & CD26(4+) n $=32$ & \\
\hline \multicolumn{6}{|l|}{ Age (year)a } \\
\hline$\leq 60$ & 1 & 10 & 18 & 19 & 0.033 \\
\hline$>60$ & 7 & 12 & 19 & 13 & \\
\hline \multicolumn{6}{|l|}{ Gendera } \\
\hline female & 3 & 12 & 18 & 13 & 0.7719 \\
\hline male & 5 & 12 & 19 & 19 & \\
\hline \multicolumn{6}{|l|}{ AJCC T classification } \\
\hline $\mathrm{T} 1$ & 2 & 5 & 7 & 4 & 0.7051 \\
\hline $\mathrm{T} 2$ & 4 & 13 & 24 & 24 & \\
\hline T3 & 2 & 4 & 4 & 4 & \\
\hline $\mathrm{T} 4$ & 0 & 2 & 3 & 0 & \\
\hline \multicolumn{6}{|l|}{ Tumor size $(\mathrm{cm})$} \\
\hline$\leq 3$ & 3 & 9 & 15 & 11 & 0.9853 \\
\hline $3-5$ & 2 & 9 & 14 & 12 & \\
\hline$\geq 5$ & 3 & 6 & 9 & 9 & \\
\hline \multicolumn{6}{|l|}{ Histological grade } \\
\hline I & 3 & 2 & 5 & 1 & 0.0185 \\
\hline II & 3 & 12 & 20 & 12 & \\
\hline III & 2 & 10 & 13 & 19 & \\
\hline \multicolumn{6}{|l|}{ Carcinomab } \\
\hline Primary & 32 & 70 & $<0.0001$ & & \\
\hline Adjacent & 102 & 0 & & & \\
\hline
\end{tabular}

account for its varied roles in different cancers (Havre et al., 2008). Further studies have shown that CD26 is a CSCs in colorectal cancer (Pang et al., 2010).

We have successfully established a new human lung cancer cell line, SPC-A-1sci, that has a high metastatic potential and is susceptible to EMT (Jia et al., 2010). A previous microarray study identified high CD26 expression in SPC-A-1sci cells compared to SPC-A-1 parental cells. To investigate the effect of CD26 on lung cancer metastasis, we generated four stably transfected cell lines in the current study: SPC-A-1-NC, SPC-A-1-

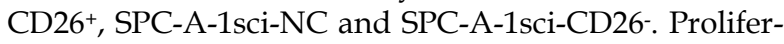
ation assays showed that CD26 expression inhibited both the growth rate and colonization of cells, a finding that was also observed by B. Pro and Wesley UV et al. (Pro and Dang, 2004; Wesley et al., 2004). The promotion of invasion and metastasis by CD26 was demonstrated by in vitro Transwell assays. Together, these results suggest that increased metastatic activity of $\mathrm{CD}^{2} 6^{+}$cells does not result from a faster growth rate but rather from the acquisition of other metastasispromoting properties.

Growing evidence suggests that EMT is a critical event in the progression of cancer metastasis (Aokage et al., 2011; Morra et al., 2012; Shih and Yang, 2011; Vuoriluoto et al., 2011; Xiao and He, 2010) and that SPC-A1sci cells have been shown to undergo EMT. Moreover, EMT is a reversible program, and carcinoma cells that have acquired a mesenchymal phenotype can revert to an epithelial state via mesenchymal-epithelial transition (MET) (Chaffer et al., 2006; Wells et al., 2008). In this study, we studied E-cadherin, $\mathrm{N}$-cadherin, vimentin, fibronectin and $\beta$-catenin as EMT/MET markers and correlated their expression with that of CD26. It is generally accepted that loss of E-cadherin mediated cell -cell adhesion precedes metastasis (Chao et al., 2010; von Burstin et al., 2009). Loss of E-cadherin is often accompanied by de novo $\mathrm{N}$-cadherin expression thus promoting cell motility and migration (Lammens et al., 2012; Wells et al., 2008). In addition, N-cadherin 
homophilic interactions between tumor cells and the surrounding tissue facilitate the migration and survival of tumor cells in distant organs. Fibronectin is an extracellular matrix glycoprotein that plays major roles in cellular differentiation, growth and migration and is involved in wound healing, embryonic development and oncogenic transformation (Ritzenthaler et al., 2008; Pankov and Yamada, 2002). Furthermore, fibronectin is a mesenchymal marker, and its expression is positively correlated with EMT (Yang et al., 2004). Fibronectin also mediates DPPIV adhesion and metastasis (Cheng et al., 2003). Vimentin, a major constituent of the intermediate filament family of proteins, is expressed ubiquitously in normal mesenchymal cells. Vimentin overexpression in cancer correlates with accelerated tumor growth, invasion, and poor prognosis. In recent years, vimentin has been recognized as a marker for EMT (Vuoriluoto et al., 2011; Satelli and Li, 2011; Luo et al., 2012). As a regulator of cadherin-mediated cell-cell adhesion, $\beta$ catenin plays an important role in EMT (Du et al., 2010; Yan et al., 2012; Sánchez-Tilló et al., 2011; Zhao et al., 2011). We found that the high CD26 expression correlated with high $\mathrm{N}$-cadherin and vimentin expression; this event was reversible and induced poorly metastatic cells to acquire morphological changes. Notably, there was no significant difference in the expression of $\beta$ catenin and fibronectin between SPC-A-1sci-CD26- and NC cells or between SPC-A-1-CD26+ and NC cells. Contrary to previous studies, we found that E-cadherin was upregulated by high CD26 expression. Usually during EMT, E-cadherin is downregulated while Ncadherin is up-regulated. However, we found that both E-cadherin and N-cadherin were up-regulated, suggesting that infected cells underwent an incomplete EMT, resulting in no morphological changes.

CD26 expression has been associated with lung cancer growth (Pro and Dang, 2004; Wesley et al., 2004). We used a lung adenocarcinoma tissue chip to determine whether there was a correlation between CD26 levels and the observed clinicopathological characteristics in lung adenocarcinoma tissues. The immunohistochemistry results showed that CD26 levels correlated with patient age and tumor histological grade, indicating that younger patients were more prone to having poorly differentiated lung adenocarcinoma and that CD26 plays an important role in this pathology.

\section{Conclusion}

CD26 can promote lung adenocarcinoma cell invasion and metastasis while also impacting the expression of the EMT-related proteins, N-cadherin and vimentin. In addition, the results suggest that CD26 is a putative factor in promoting primary lung adenocarcinoma invasion and metastasis, and is a potential prognostic marker in lung adenocarcinoma patients.

\section{Acknowledgements}

This work was supported in part by grants from the National Key Basic Research Program of China (2009CB521803) and "action plan to innovation" of the Shanghai Science and Technology fund (10140902400).

\section{References}

Aokage K, Ishii G, Ohtaki Y, Yamaguchi Y, Hishida T, Yoshida J, Nishimura M, Nagai K, Ochiai A. Dynamic molecular changes associated with epithelial-mesenchymal transition and subsequent mesenchymal-epithelial transition in the early phase of metastatic tumor formation. Int J Cancer. 2011; 28: 1585-95.

Baumann P, Cremers N, Kroese F, Orend G, Chiquet Ehrismann R, Uede T, Yagita H, Sleeman JP. CD24 expression causes the acquisition of multiple cellular properties associated with tumour growth and metastasis. Cancer Res. 2005; 65: 10783-93.

Chaffer CL, Brennan JP, Slavin JL, Blick T, Thompson EW, Williams ED. Mesenchymal-to-epithelial transition facilitates bladder cancer metastasis: Role of fibroblast growth factor receptor-2. Cancer Res. 2006; 66: 11271-78.

Chao YL, Shepard CR, Wells A. Breast carcinoma cells reexpress E-cadherin during mesenchymal to epithelial reverting transition. Mol Cancer. 2010; 9: 179.

Cheng HC, Abdel-Ghany M, Pauli BU. A novel consensus motif in fibronectin mediates dipeptidyl peptidase IV adhesion and metastasis. J Biol Chem. 2003; 278: 24600-07.

Chou TY, Chen WC, Lee AC, Hung SM, Shih NY, Chen MY. Clusterin silencing in human lung adenocarcinoma cells induces a mesenchymal-to-epithelial transition through modulating the ERK/Slug pathway. Cellular Signalling. 2009; 21: 704-11.

Dourada M, Sarmento AB, Pereira SV, Alves V, Silva T, Pinto AM, Rosa MS. CD26/DPPIV expression and 8-azaguanine response in T-acute lymphoblastic leukaemia cell lines in culture. Pathophysiology 2007; 14: 3-10.

Du R, Huang C, Bi Q, Zhai Y, Xia L, Liu J, Sun S, Fan D. URG11 mediates hypoxia-induced epithelial-to-mesenchymal transition by modulation of E-cadherin and betacatenin. Biochem Biophys Res Commun. 2010; 391: 135-41.

Guarino M, Rubino B, Ballabio G. The role of epithelialmesenchymal transition in cancer pathology. Pathology 2007; 39: 305-18.

Havre PA, Abe M, Urasaki Y, Ohnuma K, Morimoto C, Dang $\mathrm{NH}$. The role of CD26/dipeptidyl peptidase IV in cancer. Front Biosci. 2008; 13: 1634-45.

Hiramatsu H, Kyono K, Higashiyama Y, Fukushima C, Shima H, Sugiyama S, Inaka K, Yamamoto A, Shimizu R. The structure and function of human dipeptidyl peptidase IV, possessing a unique eight-bladed beta-propeller fold. Biochem Biophys Res Commun. 2003; 302: 849-54.

Inamoto T, Yamochi T, Ohnuma K, Iwata S, Kina S, Inamoto S, Tachibana M, Katsuoka Y, Dang NH. Anti-CD26 monoclonal antibody-mediated G1-S arrest of human renal 
clear cell carcinoma Caki-2 is associated with retinoblastoma substrate dephosphorylation, cyclin-dependent kinase 2 reduction, p27(kip1) enhancement, and disruption of binding to the extracellular matrix. Clin Cancer Res. 2006; 12: 3470-77.

Jia D, Yan M, Wang X, Hao X, Liang L, Liu L, Kong H, He X, Li J, Yao M. Development of a highly metastatic model that reveals a crucial role of fibronectin in lung cancer cell migration and invasion. BMC Cancer. 2010; 10: 364-75.

Kajiyama H, Shibata K, Ino K, Mizutani S, Nawa A, Kikkawa F. The expression of dipeptidyl peptidase IV (DPPIV/CD26) is associated with enhanced chemosensitivity to paclitaxel in epithelial ovarian carcinoma cells. Cancer Sci. 2010; 101: 34754 .

Kononen J, Bubendorf L, Kallioniemi A, Barlund M, Schraml P, Leighton S, Torhorst J, Mihatsch MJ, Sauter G, Kallioniemi OP. Tissue microarrays for high-throughput molecular profiling of tumor specimens. Nature Med. 1998; 4: 844-47.

Lammens T, Swerts K, Derycke L, De Craemer A, De Brouwer S, De Preter K, Van Roy N, Vandesompele J, Speleman F, Philippe J, Benoit Y, Beiske K, Bracke M, Laureys G. NCadherin in neuroblastoma disease: Expression and clinical significance. PLoS ONE. 2012; 7: e31206.

Lee P, Kupelian P, Czernin J, Ghosh P. Current concerpts in F18 FDG PET/CT-based radiation therapy planning for lung cancer. Front Oncol. 2012; 2: 71.

Lefort EC, Blay J. The dietary flavonoid apigenin enhances the activities of the anti-metastatic protein CD26 on human colon carcinoma cells. Clin Exp Metastasis. 2011; 28: 337-49.

Luo W, Fang W, Li S, Yao K. Aberrant expression of nuclear vimentin and related epithelial-mesenchymal transition markers in nasopharyngeal carcinoma. Int J Cancer. 2012; 131: 1863-73.

Morra L, Rechsteiner M, Casagrande S, von Teichman A, Schraml P, Moch H, Soltermann A. Characterization of periostin isoform pattern in non-small cell lung cancer. Lung Cancer. 2012; 76: 183-90.

Pang R, Law WL, Chu ACY, Poon JT, Lam CSC, Chow AKM, Ng L, Cheung LWH, Lan XR, Lan HY, Tan VPY, Yau TC, Poon RT, Wong BCY. A subpopulation of CD26+ cancer stem cells with metastatic capacity in human colorectal cancer. Cell Stem Cell. 2010; 6: 603-15.

Pankov R, Yamada KM. Fibronectin at a glance. J Cell Sci. 2002; 115: 3861-63.

Peinado H, Portillo F, Cano A. Transcriptional regulation of cadherins during development and carcinogenesis. Int J Dev Biol. 2004; 48: 365-75.

Pro B, Dang NH. CD26/dipeptidyl peptidase IV and its role in cancer. Histol Histopathol. 2004; 19: 1345-51.

Prudkin L, Liu DD, Ozburn NC, Sun M, Behrens C, Tang X, Brown KC, Bekele BN, Moran C. Epithelial-to-mesenchymal transition in the development and progression of adenocarcinoma and squamous cell carcinoma of the lung. Mod Pathol. 2009; 22: 668-78.

Ritzenthaler JD, Han S, Roman J. Stimulation of lung carcinoma cell growth by fibronectin-integrin signalling. Mol
BioSystems. 2008; 4: 1160-69.

Sánchez-Tilló E, de Barrios O, Siles L, Cuatrecasas M, Castells A, Postigo A. $\beta$-catenin/TCF4 complex induces the epithelial-to-mesenchymal transition (EMT)-activator ZEB1 to regulate tumor invasiveness. Proc Natl Acad Sci USA. 2011; 108: 19204-09.

Satelli A, Li S. Vimentin in cancer and its potential as a molecular target for cancer therapy. Cell Mol Life Sci. 2011; 68: 3033-46.

Shen $\mathrm{CH}$, Wu JD, Jou YC, Cheng MC, Lin CT, Chen PC, Tseng YS, Shi CS, Chen SY, Chang DC, Lee YR. The correlation between TWIST, E-cadherin, and beta-catenin in human bladder cancer. J BUON. 2011; 16: 733-37.

Shih JY, Yang PC. The EMT regulator slug and lung carcinogenesis. Carcinogenesis 2011; 32: 1299-1304.

Sun YX, Pedersen EA, Shiozawa Y, Havens AM, Jung Y, Wang J, Pienta KJ, Taichman RS. CD26/dipeptidyl peptidase IV regulates prostate cancer metastasis by degrading SDF-1/ CXCL12. Clin Exp Metastasis. 2008; 25: 765-76.

Thompson MA, Ohnuma K, Abe M, Morimoto C, Dang NH. CD26/dipeptidyl peptidase IV as a novel therapeutic target for cancer and immune disorders. Mini Rev Med Chem. 2007; 7: 253-73.

von Burstin J, Eser S, Paul MC, Seidler B, Brandi M, Messer M, von Werder A, Schmidt A, Mages J, Pagel P, Schnieke A, Schmid RM, Schneider G, Saur D. E-cadherin regulates metastasis of pancreatic cancer in vivo and is suppressed by a SNAIL/HDAC1/HDAC2 repressor complex. Gastroenterology 2009; 137: 361-71.

Vuoriluoto K, Haugen H, Kiviluoto S, Mpondi JP, Nevo J, Gjerdrum C, Lorens JB, Ivaska J. Vimentin regulates EMT induction by Slug and oncogenic H-Ras and migration by governing Axl expression in breast cancer. Oncogene 2011; 30: 1436-48.

Webb SL, Sanders AJ, Mason MD, Jiang WG. The influence of matriptase-2 on prostate cancer in vitro: A possible role of $\beta$ catenin. Oncol Rep. 2012; 2012.

Wells A, Yates C, Shepard CR. E-cadherin as an indicator of mesenchymal to epithelial reverting transitions during the metastatic seeding of disseminated carcinomas. Clin Exp Metastasis. 2008; 5: 621-28.

Wesley UV, McGroarty M, Homoyouni A. Dipeptidyl peptidase inhibits malignant phenotype of prostate cancer cells by blocking basic fibroblast growth factor signaling pathway. Cancer Res. 2005; 65: 1325-34.

Wesley UV, Tiwari S, Houghton AN. Role for dipeptidyl peptidase IV in tumor suppression of human non small cell lung carcinoma cells. Int J Cancer. 2004; 109: 855-66.

Xiao D, He J. Epithelial mesenchymal transition and lung cancer. J Thorac Dis. 2010; 2: 154-59.

Yamaguchi U, Nakayama R, Honda K, Ichikawa T, Shitashige M, Ono M, Shoji A, Sakuma T, Kuwabara H, Shimada Y, Sasako M, Shimoda T, Kawai A, Hirohashi S, Yamada T. Distinct gene expression-defined classes of gastrointestinal stromal tumor. J Clin Oncol. 2008; 26: 4100-08.

Yan D, Avtanski D, Saxena NK, Sharma D. Leptin-induced 
Yang J, Mani SA, Donaher JL, Ramaswamy S, Itzykson RA, Come C, Savagner P, Gitelman I, Richardson A, Weinberg RA. Twist, a master regulator of morphogenesis, plays an essential role in tumor metastasis. Cell 2004; 117: 927-39.

Yang J, Weinberg RA. Epithelial-mesenchymal transition: At the crossroads of development and tumour metastasis. Dev cell. 2008; 14: 818-29.

Zhao JH, Luo Y, Jiang YG, He DL, Wu CT. Knockdown of $\beta$ Catenin through shRNA cause a reversal of EMT and metastatic phenotypes induced by HIF-1a. Cancer Invest. 2011; 29: 377-82. 